\title{
UJI KINERJA DAYA DUKUNG INDIVIDU PONDASI TIANG DENGAN ALAT INSTRUMENT KONTROL PILE DRIVE ANALYZER TEST DI REFINERY UNIT V BALIKPAPAN
}

\author{
${ }^{1)}$ Sulardi \\ ${ }^{1)}$ Sekolah Tinggi Teknologi Minyak dan Gas Bumi Balikpapan \\ E-mail : sulardikm61@yahoo.com
}

\begin{abstract}
ABSTRAK
Tujuan penelitian adalah untuk memberikan gambaran rinsip dasar penggunaan alat instrumen kontrol pile drive analyzer dan metode pelaksanaanya pada pengujian daya dukung tiang pancang pondasi tangki kilang Pertamina Unit V Balikpapan. Metode penelitian yang digunakan pada penelitian adalah metode penelitian terapan (penelitian terpakai) dengan metode pendekatan studi kasus unconfidence level terhadap akurasi hasil pemancangan pondasi tiang. Penelitian ini adalah sekaligus technical notes succes story penggunaan alat instrument kontrol PDA test dilingkungan kilang PT. Pertamina RU V Balikpapan. Hasil penelitian menunjukan bahwa berdasarkan hasil uji dengan alat instrumen kontrol PDA test dapat memberikan akurasi yang baik pada daya dukung individu tiang pancang pondasi tangki sehingga tidak ada keraguan terhadap kriteria penerimaan bangunan tangki nantinya. Hasil penelitian ini merekomendasikan bahwa alat instrumen kontrol PDA cocok dan aman digunakan diarea kilang dan dapat dipergunakan untuk pekerjaan sejenis di unit kerja PT. Pertamina yang lain.
\end{abstract}

Kata kunci: Alat instrumen kontrol, pile drive analyzer, daya dukung individu.

\begin{abstract}
The aim of the study was to provide an overview of the basic principles of the use of a pile drive analyzer control instrument and its implementation method in testing the carrying capacity of Pertamina Refinery Tank Unit Balikpapan V tank foundation pile. The research method used in this research is applied research method with the method of using an unconfidence level case study on the accuracy of the results of pile foundation erection. This study is at the same time succesful story technical notes using PDA test control instrument in PT. Pertamina RU V Balikpapan. The results showed that based on the results of tests with PDA test control instruments can provide good accuracy on the carrying capacity of individual tank foundation piles so that there is no doubt about the acceptance criteria of tank building later. The results of this study recommend that PDA control instruments are suitable and safe to use in refinery areas and can be used for similar work in PT. Pertamina other.
\end{abstract}

Keywords: Control instrument, pile drive analyzer, individual bearing capacity. 


\section{PENDAHULUAN}

\section{Latar Belakang}

Penggunaan pondasi tiang pada bangunan berat dan bangunan tinggi adalah hal yang umum pada sistim konstruksi. Penggunaan jenis pondasi tiang juga dilakukan apabila tanah dasar dengan daya dukung yang cukup besar letaknya dikedalaman sehingga tidak memungkinkan menggunakan pondasi dangkal. Pondasi dangkal hanya dapat digunakan apabila bangunan yang didukung adalah bangunan ringan atau tanah dasar yang cukup keras posisinya pada kedalaman yang cukup dangkal. Pondasi tiang dipasang dengan cara dipancang dengan alat pancang manual, dipancang dengan alat pancang hydraulick jack in atau pondasi tiang dengan tiang bor. Pemilihan pondasi pancang tergantung kepada metode pelaksanaan konstruksi yang dipilih dengan target pondasi tiang dapat mendukung bangunan dengan stabil dan aman.

\section{Permasalahan}

Permasalahan yang dihadapi pada penelitian ini belum adanya metode kerja baku untuk pengujian kapasitas dukung pancang bangunan pondasi tangki. Selama ini kapasitas daya dukung tangki didasarkan dengan hasil kalendering atau berdasarkan pembacaan data penekanan mesin pancang. Namun dengan variasi kedalaman hasil pemancangan yang berbeda-beda dan hasil pembacaan manometer pemancangan yang berbeda-beda mengakibatkan timbulnya keraguan terhadap akurasi daya dukung tiang hasil pemancangan. Permasalahan yang lain adalah pekerjaan diarea kilang pengolahan minyak (refinery) tidak diijinkan untuk pekerjaan panas dengan api atau pekerjaan yang dapat menimbulkan panas atau bunga api karena dapat menimbulkan bahaya kebakaran. Untuk itu diperlukan alat kontrol yang dapat dijadikan pembanding dan tolok ukur akurasi daya dukung tiang hasil pemancangan. Dengan alasan tersebut maka penelitian ini penting untuk dilakukan untuk melakukan pengujian terhadap hasil pemancangan tiang pancang guna memberikan keyakinan akan keakuratan kapasitas daya dukung pondasi yang akan digunakan untuk mendukung tangki minyak.

\section{Tujuan Penelitian}

Tujuan yang hendak dicapai dengan penelitian ini adalah :

1. Memberikan gambaran prinsip dasar penggunaan alat instrumen kontrol pile drive analyzer pada pengujian daya dukung tiang pancang.

2. Memberikan gambaran metode pelaksanaan pengujian daya dukung tiang pancang dengan alat instrumen kontrol pile drive analyzer.

\section{Rumusan Penelitian}

Bangunan tangki adalah bangunan vital yang harus didukung oleh pondasi yang kokoh dan stabil. Jika terjadi kegagalan pada pondasi tangki akan mengalami kerusakan dan tangki tidak layak dipergunakan. Dengan hal tersebut maka dirumuskan masalah penelitian dengan pertanyaan penelitian sebagai berikut :

1. Bagaimana gambaran prinsip dasar penggunaan alat instrumen kontrol pile drive analyzer pada pengujian daya dukung tiang pancang

2. Bagaimana gambaran metode pelaksanaan pengujian daya dukung taing pancang dengan alat instrumen kontrol pile drive analyzer. 
Jika pertanyaan-pertanyaan penelitian tersebut dapat terjawab dengan baik maka tujuan penelitian dapat tercapai dengan asumsi bahwa alat instrumen kontrol dapat memberikan data daya dukung yang akurat dan alat instrumen kontrol tersebut cocok digunakan.

\section{METODE PENELITIAN}

\section{Metode Penelitian}

Metode yang digunakan pada penelitian ini adalah metode pendekatan studi kasus, yakni kasus pengujian daya dukung tiang pancang pondasi tangki dengan instrumen kontrol Pile Drive Analyzer (PDA test). Penelitian ini sekaligus sebagai technical notes succes story penggunaan instrumen kontrol tersebut pada pondasi tiang pancang bangunan tangki di kilang PT. Pertamina RU V Balikpapan. Uji PDA dilakukan terhadap pondasi tiang sampel yang lokasi pemancangannya dipilih berdasarkan data log bor dengan kondisi tanah yang berbeda. Tujuannya adalah untuk memperoleh gambaran daya dukung aksial tiang pancang, integritas dan keutuhan tiang serta gambaran besaran energi yang ditransfer ke tiang pancang.

\section{Prinsip Dasar Instrumen Kontrol Pile Drive Analyzer}

Pengujian PDA menggunakan prinsip wave mechanics dengan instrument kontrol berupa strain transducer dan accelerometer, alat ini dipasang pada tiang masingmasing dua buah dengan alasan jika salah satu instrument rusak atau tidak bekerja dengan baik dapat digantikan dengan instrument yang lainnya. Instrument kontrol dipasangkan pada garis netral dan accelerometer pada lokasi berlawanan secara diametral dan posisi palu pancang tegak lurus terhadap garis strain transducer. Alat PDA dapat mengetahui regangan yang terjadi. Pengujian PDA dilakukan selama pemancangan untuk memonitoring perkembangan daya dukung tiang. Pengujian dinamis tiang didasarkan pada analisis gelombang satu dimensi yang terjadi ketika tiang dipukul dengan hammer sesuai standar uji high strain dynamic test (ASTM D-4945-1996). Hasil pengujian berupa data tanggal pemancangan, panjang tiang dan luas penampang tiang, panjang tiang tertanam kedalam tanah serta gambar yang menunjukan lokasi tiang. Pengolahan data bisa dilakukan menggunakan case methode yaitu analisa dengan pengukuran data gaya (force) dan kecepatan (velocity) selama berlangsungnya pengujian (re-strike) dengan dipadukan perhitungan variable dinamik yang dilakukan secara real time dengan tujuan untuk mendapatkan daya dukung pondasi tiang tunggal. Dari data alat PDA selanjutnya diolah menggunakan Case Method sehingga dapat diketahui kapasitas daya dukung pondasi tiang tunggal, keutuhan tiang dengan sambungannya, dan tingkat efesiensi dari transfer energi akibat pukulan hammer. 

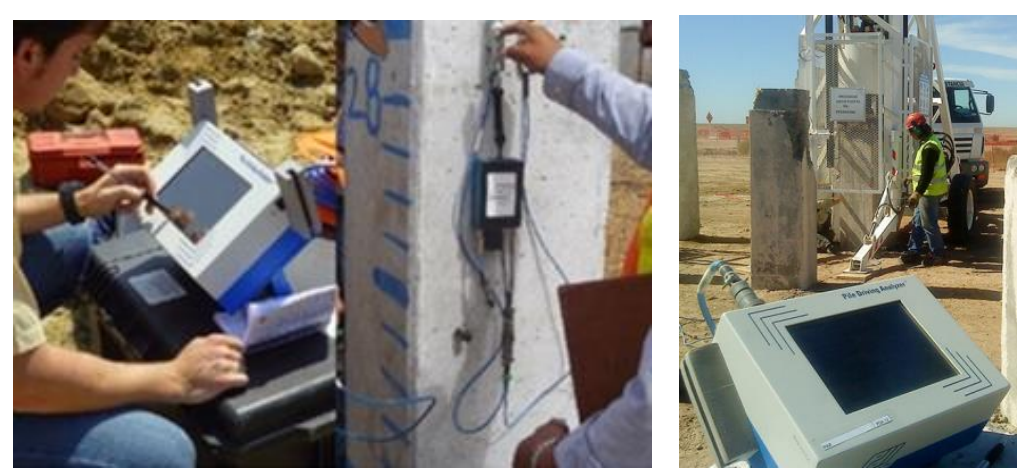

Gambar.1

Prinsip Alat Instrumen Kontrol PDA Test

\section{Bahan Penelitian}

Bahan penelitian yang dipergunakan pada penelitian ini adalah tiang pancang pondasi tangki terpasang disite, yakni sebanyak dua tiang pancang bentuk square $35 \times 35 \mathrm{Cm}$ dengan mutu beton f'c $40 \mathrm{Mpa}$ dan terdiri dari tiang dengan kedalaman pancang 24 meter tiang pancang kedalaman 4,5 meter.

\section{Peralatan Penelitian}

Peralatan yang dipergunakan pada penelitian ini adalah peralatan pengujian kapasitas daya dukung tiang pancang pondasi tangki, meliputi peralatan sebagai berikut :

1. Pile Driving Analyzer (PDA) Test

2. Strain transducer, 2 (dua) set

3. Accelerometer, 2 Set

4. Kabel penghubung (conector)

5. Peralatan kerja bantu pemasangan PDA Test, terdiri dari mesin bor listrik

6. Anchor bolt \& nuts

7. Kunci-kunci sesuai kebutuhan

8. Peralatan keselamatan kerja dan Alat pelindung diri

9. Peralatan lain sesuai kebutuhan dilapangan.
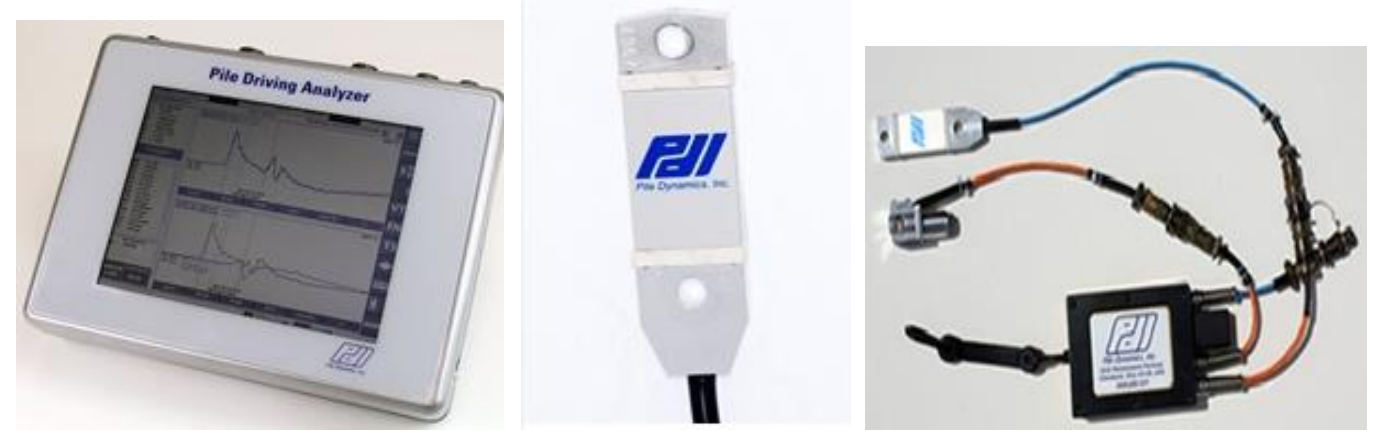

Gambar. 2

Alat PDA, Strain transducer dan Accelerometer 


\section{Metode Pengujian Tiang Pancang Dengan Instrumen Kontrol Pile Drive Analyzer test}

1. Persiapkan tiang pancang untuk PDA minimal $1,5 \mathrm{~m}$ atau $3 \mathrm{xD}$ (tiga kali diameter tiang), kemudian dihitung panjang tiang sesuai dengan yang direncanakan

2. Siapkan arus listrik AC dengan daya sesuai kebutuhan (pada umumnya alat PDA menggunakan daya $220 \mathrm{~V}, 60 \mathrm{~Hz}$ dan $30 \mathrm{Amp}$ ), sumber listrik yang berasal dari mesin las atau daya tidak stabil tidak boleh digunakan untuk alat PDA Test

3. Siapkan tenda atau sarana perlindungan untuk melindungi alat PDA dan pekerja dari kondisi panas matahari, air, angin dan temperature tinggi. Jika diperlukan tempat perlindungan dengan suhu 20-30 derajat Celcius. Tenda pelindung Alat PDA ditempatkan kurang lebih 15-20m dari tiang, sehingga kabel PDA dapat sampai dengan komputer PDA dan operator dapat mengawasi tiang.

4. Siapkan lokasi penempatan/ pemasangan baut accelerator dan baut transducer dengan cara mengebor dengan mesin bor sampai dengan total 16 (enam belas) lubang baut di kedua sisi atau 4 sisi tiang (ssuai arahan PDA Test Engineer) dengan perkiraan jarak sama dengan 3 (tiga) kali diameter tiang di bawah kepala tumpukan.

5. Pastikan bahwa alat uji yang digunakan dalam kondisi prima/ sehat, baik komputer, kabel, dan sensor yang dipakai mempunyai sertifikasi kabilbrasi yang update (kalibrasi alat minimal 2 tahun sekali).

6. Pastikan bahwa Testing Engineer harus mengerti dan memahami dengan baik dan benar prinsip dasar tentang PDA test, kapasitas aksial tiang pondasi dalam, serta memahami penggunaan parameter yang digunakan dalam PDA test

7. Pastikan bahwa kondisi kepala tiang uji harus rata, kondisi dari kepala tiang hingga dasar tiang terhadap tanah harus rata dan bagus (tidak ada indikasi keropos atau cacat), umur beton sudah memenuhi syarat $>28$ hari, dan hasil test tekan betonnya sudah sesuai dengan spesifikasi design

8. Pastikan bahwa berat hammer yang digunakan harus sesuai yakni antara 1- $2 \%$ dari daya dukung ultimate, dengan ukuran hammer yang proporsional dengan ukuran tiang.

9. Pastikan bahwa untuk pengetesan yang menggunakan drop hammer harus menggunakan ladder/selongsong yang tepat untuk menjaga eksentrisitas tumbukan hammer. Tumbukan yang tidak sentris menyebabkan kualitas data PDA test tidak representative (sering disebut sebagai GIGO : Garbage in garbage out)

10.Safety saat pelaksanaan test harus sangat diutamakan baik terhadap sensor dari kemungkinan rusak karena impact dari hammer dan sebagainya, dan juga safety dari alat pendukung saat pelaksaan test, terutama semua orang/pekerja yang terlibat pada saat pengetesan

11.Pengujian PDA Test dilaksanakan sesuai ASTM D-4945 sebagai berikut :

a. Memasang 2 Pcs sensor yaitu strain transduser dan accelerometer transduser pada sisi tiang dengan posisi saling berhadapan, kedua sensor tersebut mempunyai fungsi ganda, masing-masing menerima perubahan percepatan dan regangan. 
b. Gelombang tekan akan merambat dari kepala tiang ke ujung bawah tiang (toe) setelah itu gelombang tersebut akan dipantulkan kembali menuju kepala tiang dan ditangkap oleh sensor.

c. Gelombang yang diterima sensor secara otomatis akan disimpan oleh komputer.

d. Rekaman hasil gelombang menjadi dasar bagi analisa dengan menggunakan program TNOWAVE-TNODLT, gelombang pantul berupa reaksi tanah akibat kapasitas dukung ujung dan gerak akan memberikan kapasitas dukung termobilisasi (mobilized capacity).

e. Hasil Pengujian Angka penurunan yang diambil sebagai immediate displacement saat beban mencapai kapasitas dukung dengan safety factor. 2.0, dan tidak menyatakan penurunan konsolidasi

12.Indikator tolok ukur keberhasilan metode pengujian daya dukung pondasi tiang dengan alat instrumen kontrol PDA test adalah :

a. Uji PDA Test selesai dikerjakan, hasilnya dicatat dan didokumentasikan dengan baik

b. Laporan hasil PDA test disusun dengan pengawasan seorang ahli geoteknik (geotechnical engineer) yang berpengalaman, mengerti dan memahami dengan baik dan benar tentang pengujian PDA Test

c. Safety Factor minimal pada PDA test adalah 2.25 dari daya dukung design

d. Semua prosedur pengujian PDA Test telah memenuhi standard yang ditentukan sesuai Standard ASTM D- 4945 terbaru (last edition)

e. Mentaati peraturan keselamatan kerja dengan baik dan tidak terjadi accident.

\section{Hasil Penelitian}

\section{HASIL \& PEMBAHASAN}

Data hasil pengujian pondasi tiang pancang pondasi tangki dengan alat instrumen kontrol PDA menunjukan hasil sebagai berikut.

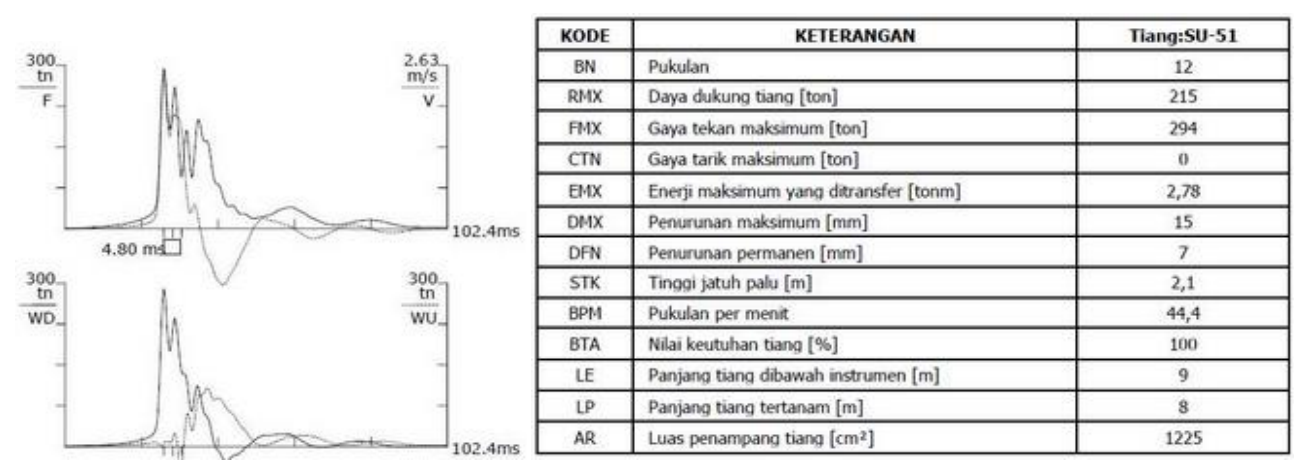



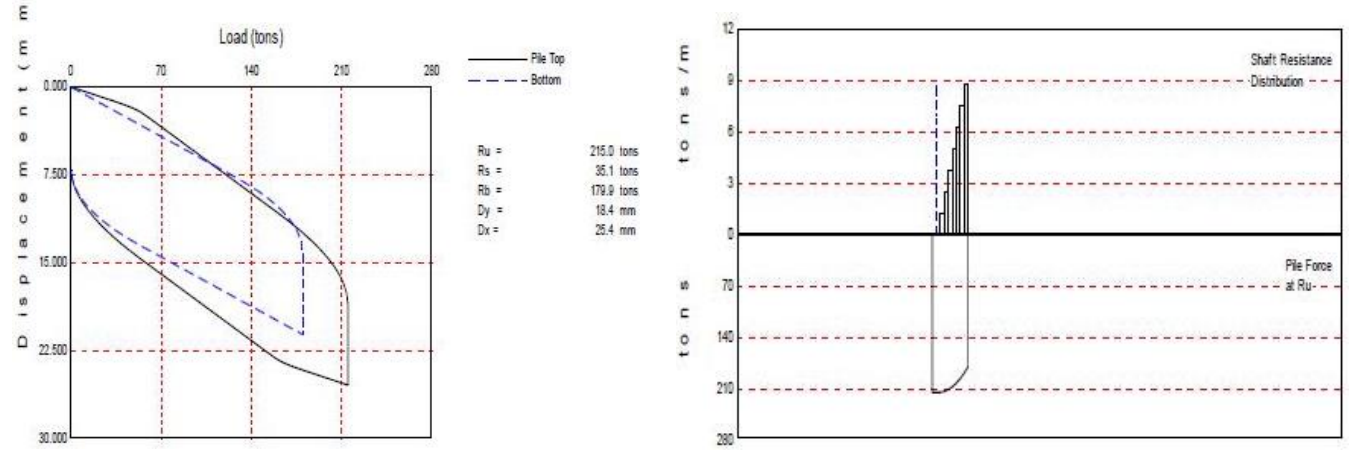

Telah dilakukan pengujian pondasi tiang pancang dengan kedalaman 24 meter dan 4,5 meter dengan metode uji PDA Test sesuai TKI No.C-020/E15220/2016-S9 dan standard ASTM D-4945-1996. Hasil uji pembebanan dinamis meliputi kapasitas dukung termobilisasi berupa beban kerja per-tiang. 205-215 ton, ditentukan oleh beban dan energy dengan maksimum yang dapat ditransfer adalah 2,78 tonm dan tiang pancang dalam kondisi utuh, maka kapasitas dukung termobilisasi dengan dengan safety factor. 2.0 yang dihasilkan nilainya memenuhi target beban rencana dengan penurunan (displacement) dan masih dalam batas yang aman. Dengan hasil-hasil penelitian tersebut maka pertanyaan-pertanyaan penelitian telah dapat terjawab dengan baik sehingga tujuan penelitian telah dapat dicapai. Selanjutnya asumsi bahwa alat instrumen kontrol yang diprediksi dapat memberikan data daya dukung yang akurat dapat dibuktikan dan alat instrumen kontrol tersebut terbukti cocok dan aman digunakan dilingkungan area kilang.

\section{Pembahasan}

Uji kapasitas daya dukung pondasi tiang tunggal dengan alat instrumen kontrol pile drive analyzer tidak menggunakan sumber panas terbuka, tidak menimbulkan panas, tidak mengakibatkan bahaya flash dan kebakaran. Secara kualitas, kapasitas data uji daya dukung individual tiang dengan PDA test, tiang pada kedalaman. 4.5 meter adalah 205 ton, penutunan maksimum $15 \mathrm{~mm}$ dan settlement permanen yang terjadi adalah $7 \mathrm{~mm}$ dan daya dukung tiang dengan kedalaman 24 meter adalah 215 ton dengan settlement. $0.75 \mathrm{~mm}$, sesuai spesifikasi. Sacara cost dengan pengujian ada potensi menekan biaya sebesar Rp 4.49 akibat resiko potensi residual risk telah dieliminir dengan penambahan 2 Pcs tiang pancang diluar tiang pancang yang kedalamannya tidak sesuai spesifikasi. Secara delivery berdasarkan hasil uji PDA ini telah direkomendasi perbaikan daya dukung dengan penambahan 2 Pcs tiang disisi tiang pancang terpasang. Secara safety kondisi tiang pancang pada safe condition, setelah dilakukan perbaikan daya dukung dengan PDA test pondasi dinyatakan aman (Safe Condition). Dan secara moral pekerja terlibat pekerjaan konfiden, dapat mengatasi permasdalahan dilingkungan kerja sendiri dengan baik dan aman.

\section{Kesimpulan}

\section{PENUTUP}

1. Hasil pemancangan dengan alat hydraulick in cukup baik, energi alat pemancang dapat tersalurkan dengan baik pada tiang pancang dengan rata-rata energi tersalurkan adalah $65-70 \%$ total energi alat pancang 
2. Alat instrumen kontrol pile drive analyzer (PDA Test) cocok dan sesuai digunakan untuk mengukur kapasitas daya dukung aktual tiang pancang pondasi tangki di kilang PT. Pertamina RU V Balikpapan

\section{Saran-saran}

1. Penggunaan alat instrumen kontrol PDA terbukti cocok dan aman digunakan untuk pengujian daya dukung tiang pancang pondasi tangki, dapat digunakan untuk pengujian tiang pancang maupun tiang bor pondasi struktur maupun peralatan sejenis di area kilang PT. Pertamina RU V

2. Sebelum pelaksanaan uji PDA agar dilakukan brain stroming dan sosialisasi prosedur kerja pengujian sebagai bentuk sharing knowledge.

\section{Ucapan Terimakasih}

Dengan selesainya penelitian ini penulis mengucapkan terimakasih kepada kawan-kawan Project Engineering PT. Pertamina RU V Balikpapan, kawankawan PT. Adhi Karya Jakarta dan kawan-kawan PT. Geo Pondasi Testing Jakarta yang telah banyak membantu kelancaran dan selesainya penelitian ini.

\section{DAFTAR PUSTAKA}

ASTM D-4945 - 1996, 1996, Standard Test Method for High-Strain Dynamic Testing of Deep Foundations.

G. E, Likins and F, Rausche, 2004, Correlation of CAPWAP with Static Load Tests. Proceedings of the Seventh International Conference on the Application of Stresswave Theory to Piles: Petaling Jaya, Selangor, Malaysia

Hardjasaputra, H., Ibrahim, M., Tampubolon,R, 2006, Strategi Pencegahan Kegagalan Pondasi dengan Melakukan Rangkaian Uji Coba Beban Serta Uji Integritas Tiang Pondasi, Seminar Jurusan Teknik Sipil UPH, Jakarta. Robinson, B., Rausche, F.,

Likins, G. E., Ealy, C, 2002, Dynamic Load Testing of Drilled Shafts at National Geotechnical Experimentation Sites, Deep Foundations 2002, An Int. Perspective on Theory, Design, Construction, \& Performance, Orlando, FL ASCE, GSP 116.

Setio, HD, Setio, S, Martha,D, Kamal, B.r dan Nasution, S, 2000, Analisis Daya Dukung Tiang Pancang dengan Metode Dinamik, Prosiding Pertemuan Ilmiah Tahunan IV, INDO-GEO 2000 HATTI, Jakarta, V 27 V 35.

Sulardi, 2016, Kinerja Daya Dukung Individu Pondasi Tiang Bangunan Apartemen Dengan Uji Pile Driving Analyzer Test Di RU V Balikpapan, PT. Pertamina RU V, Balikpapan

Sulardi, 2017, Uji Daya Dukung Pondasi Tiang Tunggal Pondasi Tangki Dengan Alat Instrumen Kontrol Pile Drive Analyzer, PT. Pertamina RU V, Balikpapan

TKI No. C-020/ E15220/2016-S9 Rev.0, 2016, Pengujian Daya Dukung Aksial Tiang Pancang Dengan Metode Pile Driving Analyzer Di Pertamina RU $V$, PT. Pertamina RU V, Balikpapan. 